\title{
Retinal venous pressure in chronic smokers
}

\author{
Zakieh Vahedian ${ }^{1}$, Heidar Amini ${ }^{1}$, Mehdi Hosseini Tehrani ${ }^{1}$, Reza Zarei ${ }^{1}$, Sasan Moghimi ${ }^{1}$, Maneli Mozaffarieh ${ }^{2}$ \\ and Ghasem Fakhraie ${ }^{1 *}$
}

\begin{abstract}
Background: The overall aim of this study was to determine retinal venous pressure (RVP) in healthy chronic smokers and compare values to those of healthy non-smokers.

Methods: Both eyes of 25 healthy chronic smokers and 41 healthy non-smokers were included. Measurements of RVP were performed by means of contact lens ophthalmodynamometry. Ophthalmodynamometry is done by applying increasing force on the eye via a contact lens. If a spontaneous venous pulsation was present, it was noted. If not, the compressive force was increased until the first venous pulsation was detected, and the measurement value was fixed and read. RVP was calculated as the sum of pressure increase induced by the instrument and intraocular pressure.

Results: Smokers had a significantly higher frequency of spontaneous venous pulsations than non-smokers $(p<0.001)$. Mean values of RVP were slightly lower in smokers than in non-smokers: 15.3 and 15.5 (smokers) versus 15.9 and 16.2 (non-smokers) for the right and left eye, respectively; however, the difference in RVP between the two groups did not reach significance. There was no significant difference in blood pressure between the two groups, but heart rate was significantly higher in smokers $(p=0.043)$.
\end{abstract}

Conclusions: RVP values may differ in healthy smokers than in non-smokers. Therefore, smoking habits should be considered when interpreting RVP results.

Keywords: Retinal venous pressure, Ophthalmodynamometric force, Smoking, Predictive preventive and personalized medicine

\section{Overview}

Cigarette smoking is associated with an increased risk for vascular disease [1-3]. The positive relationship between smoking and coronary heart disease deaths in men was first reported in 1940 [4], with the risk up until today being strongly dose related [5]. Smoking nearly doubles the risk of ischemic stroke [6] and more than doubles the number of DNA breaks at a time in the healthy persons' circulating leukocytes [7]. Smokers are at risk for a variety of chronic vascular diseases including peripheral arterial disease, stroke, heart attack, abdominal aortic aneurysm and subsequent death $[8,9]$. The acute cardiovascular effects of tobacco smoking have been attributed mainly to nicotine. Nicotine releases catecholamines via stimulation of the sympathetic ganglia $[10,11]$.

\footnotetext{
* Correspondence: drfakhraee@yahoo.com

${ }^{1}$ Glaucoma Service, Farabi Eye Hospital, Tehran University of Medical

Sciences, Qazvin Sq., South Kargar Ave., Tehran 1336616351, Iran

Full list of author information is available at the end of the article
}

Smoking elicits an increase in sympathoadrenergic tone resulting in increase in the heart rate, blood pressure and blood levels of catecholamines such as adrenaline $[8,12,13]$. The effect of acute exposure of nicotine on vascular resistance, however, is somewhat controversial [14-16]. Some evidence suggests that vascular resistance in chronic smokers may even be lower than that in non-smokers [17].

Little is known about the hemodynamic effects of nicotine on ocular circulation. In 1993, Rojanapongpun and Drance found that small doses of nicotine (Nicorette gum) increased blood flow velocities in the ophthalmic artery of glaucoma patients whereas it significantly decreased finger blood flow [18]. The authors, however, did not state whether the participants were smokers or not. In 1994, Morgado et al. [19] found a decreased retinal blood flow in acute smokers, and 1 year later, Williamson et al. [20] found that cigarette smoking was associated with lower ophthalmic artery velocities. Some years later in 1997, Kaiser and Flammer observed that in

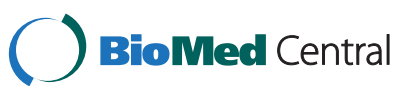

(c) 2015 Vahedian et al.; licensee BioMed Central. This is an Open Access article distributed under the terms of the Creative Commons Attribution License (http://creativecommons.org/licenses/by/4.0), which permits unrestricted use, distribution, and reproduction in any medium, provided the original work is properly credited. The Creative Commons Public Domain Dedication waiver (http://creativecommons.org/publicdomain/zero/1.0/) applies to the data made available in this article, unless otherwise stated. 
the majority of the measured ocular vessels, blood flow velocity was higher in smokers than in non-smokers [17]. Recently, Kalpana and colleagues observed that in smokers, normoxic hypercapnia resulted in a significant increase in velocity flow and total venous retinal blood flow [21].

Retinal venous pressure (RVP) is an important parameter in the clinical assessment of retinal blood flow. It is assumed that in healthy people, RVP commonly equals the intraocular pressure (IOP); in other words, healthy people commonly have a spontaneous venous pulsation [22-26]. This assumption, however, is not always correct for healthy people [22,25-27] neither for those with a disease (e.g. glaucoma) [27-33].

Taking the above information into account, we wondered whether RVP in healthy chronic smokers would be any different to healthy non-smokers. The overall aim of this study was to measure RVP in healthy chronic smokers (during a smoking-free period) and compare values to healthy non-smokers.

\section{Methods}

In this cross sectional case-control study, participants were invited by an ophthalmologist (ZV) of the Farabi Eye Hospital in Tehran to participate in this study on a volunteer basis and receive a routine ophthalmological checkup in return. The study was approved by the local ethical committee of Tehran University of Medical Sciences, and all participants gave their consent to participate in the study. Included were 25 smokers and 41 people who did not smoke at all. Excluded were subjects under local or systemic medication as well as subjects with a history of eye or general disease. None of the participants had any pathological findings (other than increased retinal venous pressure) in their routine ophthalmological examination. The non-contact examination was a part of our routine ophthalmoscopic examination of the fundus of the patients. Blood pressure examination and heart rate were measured in all participants. RVP was measured in both eyes of all participants by means of an ophthalmodynamometer. All measurements were performed by the same ophthalmologist $(\mathrm{ZV})$. The interval between the last cigarette smoked and the time of RVP measurement was 30 to $60 \mathrm{~min}$.

RVP was measured in both eyes by ophthalmodynamometry (IMEDOS, Jena, Germany) [34]. This device consists of a conventional Goldmann contact lens fitted with a pressure sensor at its outer margin where the Goldmann contact lens is usually held during an ophthalmoscopic examination. The contact lens is fitted to an outer ring by strain gauges which give an electrical signal. This signal is linearly related to the force by which the contact lens is attached to the eye. It is given to the input of a central unit by a thin flexible cable.
This central unit has the size of a pocket calculator. It shows the increase of the IOP induced by the force applied on a LCD display. The conversion from force to pressure is based on a biophysical calibration $[35,36]$.

Ophthalmodynamometry was conducted by applying increasing force to the eye via the contact lens. This applied pressure can be read as a pressure increase on the attached LCD screen based on a calibration curve. Any small pulsatile synchronous movement of the central retinal vein or its major branches inside the optic disc was noted as spontaneous pulsation. In short, after placing the CLD on the eye, the ONH was brought into sight. If a spontaneous venous pulsation was present, it was noted. If not, the compressive force was increased until the first venous pulsation was detected, and the measurement value was fixed and read. RVP was calculated as the sum of pressure increase induced by the instrument and IOP.

\section{Statistical analysis}

Statistical analysis was performed using SPSS 16.0 software (SPSS Inc, Chicago, Illinois, USA). Because of the small sample size, non-parametric tests were used to analyze the data. Comparison of quantitative variables between smokers and non-smokers was performed using Mann-Whitney $U$ test. The difference in categorical data was evaluated using chi-square test. A $p$ value $<0.05$ was considered statistically significant.

\section{Results}

The patient characteristics are listed in Table 1. The mean number of cigarettes smoked per day by smokers was 25 (SD 8.84) with a range of 10 to 40.

Smokers had a significantly higher frequency of spontaneous venous pulsations than non-smokers $(86.0 \%$ vs $51 \%, p<0.001)$. Mean values of RVP were slightly lower in smokers than in non-smokers: 15.3 and 15.5 (smokers) versus 15.9 and 16.2 (non-smokers) for the right and left eye, respectively; the difference in RVP, however, between the two groups did not reach significance (Figure 1). There was no significant difference in blood pressure between the two groups, but heart rate was significantly higher in smokers $(p=0.043$, Table 1$)$.

No significant differences were accounted for in the IOP values between the smoking and non-smoking group or between the two eyes of patients within each group (Table 1).

\section{Discussion}

In our study, smokers had a slightly lower mean RVP and a higher frequency of spontaneous retinal vein pulsations in comparison to age- and sex-matched healthy non-smokers. Moreover, $49 \%$ of the non-smoking healthy participants lacked a spontaneous venous pulsation, a 
Table 1 Patient characteristics of the two groups

\begin{tabular}{|c|c|c|c|}
\hline Variable & Smokers & Non-smokers & $p$ value \\
\hline Number & 25 & 41 & \\
\hline Age, mean $(S D)^{a}$ & $44.16(10.65)$ & $42.7(13.1)$ & n.s. \\
\hline Gender (M/F) & $18 / 7$ & $20 / 21$ & n.s. \\
\hline Systolic BP (mmHg), mean (SD) ${ }^{a}$ & $123.2(21.0)$ & $120.6(28.7)$ & n.s. \\
\hline Diastolic BP (mmHg), mean (SD) ${ }^{a}$ & $71.2(11.9)$ & $68.9(14.1)$ & n.s. \\
\hline Heart rate (beat/min), mean (SD) ${ }^{a}$ & $77.5(7.3)$ & $74.0(9.3)$ & $0.043^{\mathrm{a}}$ \\
\hline IOP right eye $(\mathrm{mmHg})$, mean $(\mathrm{SD})^{\mathrm{a}}$ & $14.2(2.9)$ & $13.0(2.4)$ & n.s. \\
\hline IOP left eye $(\mathrm{mmHg})$, mean $(\mathrm{SD})^{\mathrm{a}}$ & $14.6(3.1)$ & $13.1(2.4)$ & n.s. \\
\hline
\end{tabular}

$M$ male, $F$ female, $B P$ blood pressure, $I O P$ intraocular pressure, n.s. $=$ not significant.

andependent Mann-Whitney $U$ test.

value which is higher than those of previous reports. How can we explain these observations?

Reports of spontaneous venous pulsations in healthy subjects vary. Whereas some reports state that only approximately $2 \%$ of the healthy population does not have spontaneous venous pulsations [25], others report the lack of a spontaneous venous pulsation in approximately $10 \%-24 \%$ of healthy subjects $[22,25-27,37]$. Our results of $49 \%$ suggest that these values may possibly vary from population to population, with an increased RVP being more frequent in healthy people than previously accounted for.

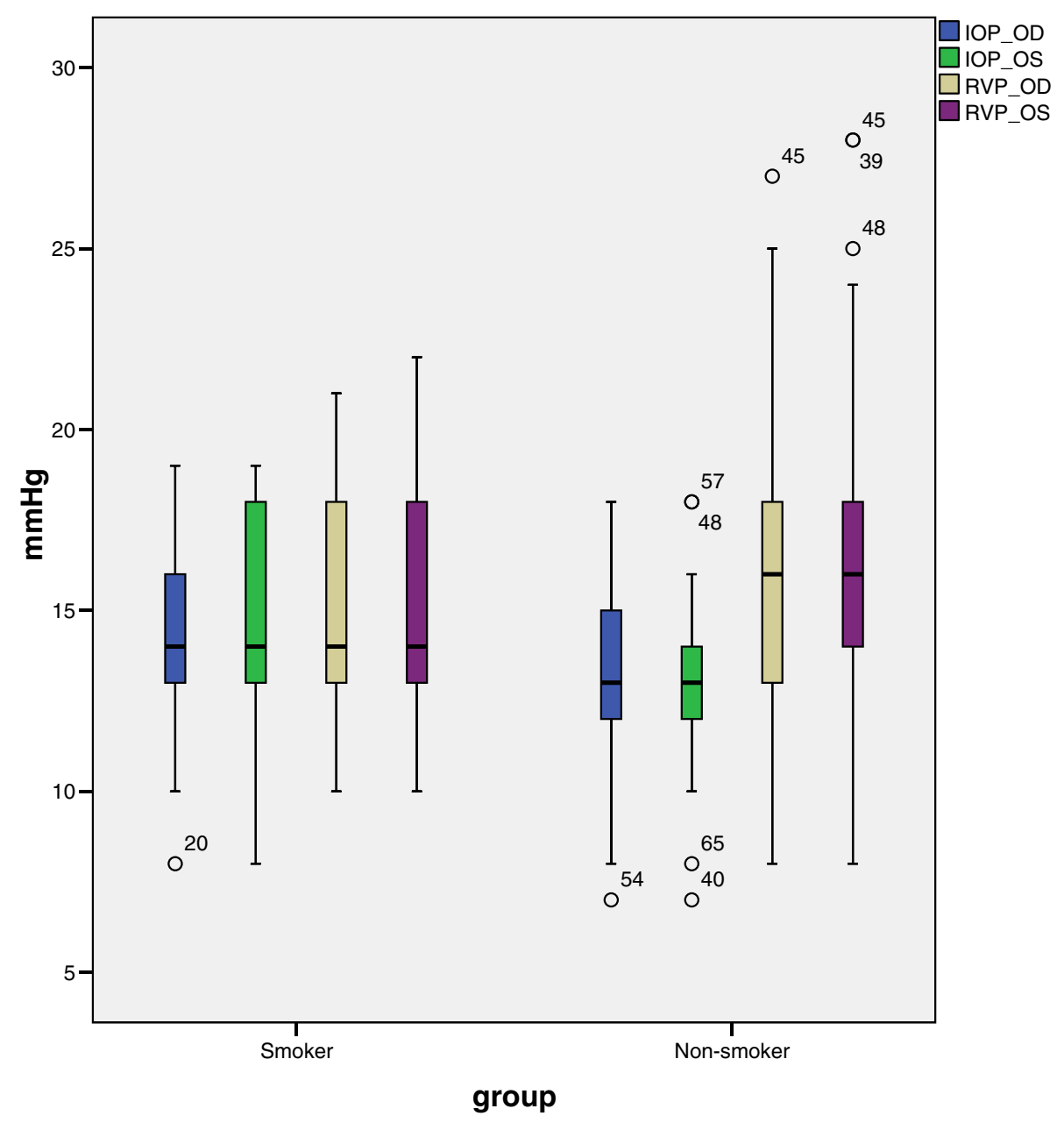

Figure 1 Box plot of intraocular pressure (IOP) and retinal venous pressure (RVP) in both eyes of smokers and non-smokers. OD = right eye, OS = left eye. 
Findings of a higher frequency of spontaneous venous pulsation in smokers go hand in hand with results of previous studies showing a significantly higher blood flow velocity in the majority of the ocular vessels of smokers. Back in 1997, Kaiser and Flammer [17] discussed that the smoke of a cigarette besides many other components contains approximately $2 \%-6 \%$ carbon monoxide [38] leading to an increase in carboxyhemoglobin levels up to $3 \%-15 \%$ in smokers compared to a value of less than $1.5 \%$ in non-smokers [39]. The relative oxygen deficit would provoke regulatory effects leading to downstream vasodilation and an increase in blood flow velocity. Our results support this argument; not only was the frequency of spontaneous venous pulsations higher in smokers but also mean values of RVP were slightly lower in smokers compared to non-smokers. Nevertheless, it should be noted that differences in the methodology amongst various institutions such as the method of ophthalmoscopy or the pulsation criterion set by the examiner to define as spontaneous venous pulsation may lead to different results. Our definition of a spontaneous venous pulsation was the same as that of our colleagues Stodtmeister et al. [33].

There was no difference in systolic or diastolic blood pressure in the two groups. These data are somewhat paradoxical because cigarette smoking elicits an increase in sympathoadrenergic tone, resulting in the elevation of blood pressure $[40,41]$. We can only hypothesize what is happening, yet this discrepancy may be explained as follows. Initially, a vasoconstriction mediated by nicotine causes an increase in systolic blood pressure [42]. This phase is followed by a decrease in blood pressure as a consequence of depressant effects played chronically by nicotine itself [43]. Moreover, healthy cigarette smokers have an increased sensitivity to endogenous endotheliumdependent and endothelium-independent vasodilators [44]. Assuming that the increase in adrenergic tone caused by nicotine is counteracted to some degree by the increased sensitivity to endogenous vasodilator stimuli, the equalization in blood pressure between the two groups may be explained.

This study has some limitations that should be kept in mind; the sample size is small with specific reference to the smoking group. More studies with larger sample sizes can help us infer more reliable assumptions about our population. Moreover, differences in RVP between the two groups may have reached significance had the sample size been large enough.

\section{Conclusion}

Altogether, RVP values appear to be different in healthy smokers than in non-smokers. Future study designs of RVP measurements should, therefore, take into account the differences between smokers and non-smokers.

\section{Abbreviations}

RVP: Retinal venous pressure; IOP: Intraocular pressure; BP: Blood pressure.

\section{Competing interests}

The authors declare that they have no competing interests.

\section{Authors' contributions}

ZV was responsible for patient collection, acquisition of data and analysis. HA and RZ jointly drafted the manuscript. MHT helped recruit patients for the study and helped design and coordinate the study. SM was responsible for the study design and data analysis. MM was responsible for the conception and design, drafting the manuscript and revising it critically for important intellectual contents. GF was responsible for data analysis and final approval of the manuscript. All authors read and approved the final manuscript.

\section{Acknowledgements}

We would like to thank the co-owner of the ophthalmodynamometer, Prof. J Flammer (MD), for providing an ophthalmodynamometer to perform this study.

\section{Author details}

${ }^{1}$ Glaucoma Service, Farabi Eye Hospital, Tehran University of Medical Sciences, Qazvin Sq., South Kargar Ave., Tehran 1336616351, Iran.

${ }^{2}$ Department of Ophthalmology, University of Basel, Basel, Switzerland.

Received: 11 December 2014 Accepted: 3 March 2015

Published online: 08 April 2015

\section{References}

1. Polonsky TS, Liu K, Tian L, Carr J, Carroll TJ, Berry J, et al. High-risk plaque in the superficial femoral artery of people with peripheral artery disease: prevalence and associated clinical characteristics. Atherosclerosis. 2014;237(1):169-76.

2. Armstrong EJ, Wu J, Singh GD, Dawson DL, Pevec WC, Amsterdam EA, et al. Smoking cessation is associated with decreased mortality and improved amputation-free survival among patients with symptomatic peripheral artery disease. J Vasc Surg. 2014;60(6):1565-71.

3. Odden MC, Yee LM, Arnold AM, Sanders UL, Hirsch C, deFilippi C, et al. Subclinical vascular disease burden and longer survival. J J Am Geriatr Soc. 2014;62(9):1692-8.

4. English JP, Willius FA, Berkson J. Tobacco and coronary disease. JAMA. 1940;115(16):1327-9.

5. Kreuz J, Skowasch D, Kamrath P, Lorenzen H, Tiyerili V, Linhart M, et al. Influence of smoking dosage and chronic obstructive lung disease on the incidence of appropriate therapies and mortality in patients with structural heart disease and an implantable cardioverter defibrillator. Pacing Clin Electrophysiol. 2015:38(1):71-6

6. Shah RS, Cole JW. Smoking and stroke: the more you smoke the more you stroke. Expert Rev Cardiovasc Ther. 2010;8(7):917-32.

7. Mozaffarieh M, Konieczka K, Hauenstein D, Schoetzau A, Flammer J. Half a pack of cigarettes a day more than doubles DNA breaks in circulating leukocytes. Tob Induc Dis. 2010;8(1):1-4.

8. Middlekauff HR, Park J, Moheimani RS. Adverse effects of cigarette and noncigarette smoke exposure on the autonomic nervous system: mechanisms and implications for cardiovascular risk. J Am Coll Cardiol. 2014;64(16):1740-50

9. Lloyd-Jones DM. Cardiovascular health and protection against CVD: more than the sum of the parts? Circulation. 2014;130(19):1671-3.

10. Grady S, Marks MJ, Wonnacott S, Collins AC. Characterization of nicotinic receptor-mediated $[3 \mathrm{H}]$ dopamine release from synaptosomes prepared from mouse striatum. J Neurochem. 1992;59(3):848-56.

11. Rapier C, Lunt GG, Wonnacott S. Stereoselective nicotine-induced release of dopamine from striatal synaptosomes: concentration dependence and repetitive stimulation. J Neurochem. 1988;50(4):1123-30.

12. Gać P, Poręba R, Poręba M, Mazur G, Sobieszczańska M. Effect of environmental exposure to cigarette smoke on blood pressure in 24-hour ambulatory blood pressure monitoring in patients with essential hypertension. Pol Arch Med Wewn. 2014;124(9):436-42.

13. Walker JF, Collins LC, Rowell PP, Goldsmith LJ, Moffatt RJ, Stamford BA. The effect of smoking on energy expenditure and plasma catecholamine and nicotine levels during light physical activity. Nicotine Tob Res. 1999;1(4):365-70. 
14. Brunel P, Girerd X, Laurent S, Pannier B, Safar M. Acute changes in forearm haemodynamics produced by cigarette smoking in healthy normotensive non-smokers are not influenced by propranolol or pindolol. Eur J Clin Pharmacol. 1992;42(2):143-6.

15. Trap-Jensen J. Effects of smoking on the heart and peripheral circulation. Am Heart J. 1988;115(1 Pt 2):263-7.

16. Lee BL, Benowitz NL, Jacob P. Influence of tobacco abstinence on the disposition kinetics and effects of nicotine. Clin Pharmacol Ther. 1987;41(4):474-9.

17. Kaiser HJ, Schoetzau A, Flammer J. Blood flow velocity in the extraocular vessels in chronic smokers. Br J Ophthalmol. 1997;81(2):133-5.

18. Rojanapongpun $P$, Drance SM. The effects of nicotine on the blood flow of the ophthalmic artery and the finger circulation. Graefes Arch Clin Exp Ophthalmol. 1993;231(7):371-4.

19. Morgado PB, Chen HC, Patel V, Herbert L, Kohner EM. The acute effect of smoking on retinal blood flow in subjects with and without diabetes. Ophthalmology. 1994;101(7):1220-6.

20. Williamson TH, Lowe G, Baxter GM. Influence of age, systemic blood pressure, smoking, and blood viscosity on orbital blood velocities. Br J Ophthalmol. 1995;79(1):17-22.

21. Rose K, Flanagan JG, Patel SR, Cheng R, Hudson C. Retinal blood flow and vascular reactivity in chronic smokers. Invest Ophthalmol Vis Sci. 2014;55(7):4266-76.

22. Legler $U$, Jonas JB. Assessment of the spontaneous pulsations of the central retinal vein in daily ophthalmic practice. Clin Experiment Ophthalmol. 2007;35(9):870-1.

23. Lorentzen SE. Incidence of spontaneous venous pulsation in the retina. Acta Ophthalmol (Copenh). 1970;48(4):765-70.

24. Meyer-Schwickerath R. Occlusion site and occlusion time of central artery occlusions: diagnostic references caused by changes in the collapse phenomenon of the central artery in ophthalmodynamometry. Fortschr Ophthalmol. 1989;86(6):756-9.

25. Morgan WH, Hazelton ML, Azar SL, House PH, Yu DY, Cringle SJ, et al. Retinal venous pulsation in glaucoma and glaucoma suspects. Ophthalmology. 2004;111(8):1489-94.

26. Jacks AS, Miller NR. Spontaneous retinal venous pulsation: aetiology and significance. J Neurol Neurosurg Psychiatry. 2003;74(1):7-9.

27. Fang $L$, Baertschi M, Mozaffarieh $M$. The effect of flammer-syndrome on retinal venous pressure. BMC Ophthalmol. 2014;14(1):121.

28. Jonas JB. Central retinal artery and vein collapse pressure in eyes with chronic open angle glaucoma. Br J Ophthalmol. 2003;87(8):949-51.

29. Balaratnasingam C, Morgan WH, Hazelton ML, House PH, Barry CJ, Chan H, et al. Value of retinal vein pulsation characteristics in predicting increased optic disc excavation. Br J Ophthalmol. 2007;91(4):441-4.

30. Morgan WH, Balaratnasingam C, Hazelton ML, House PH, Cringle SJ, Yu DY. The force required to induce hemivein pulsation is associated with the site of maximum field loss in glaucoma. Invest Ophthalmol Vis Sci. 2005;46(4):1307-12.

31. Abegão PL, Vandewalle E, De Clerck E, Marques-Neves C, Stalmans I. Lack of spontaneous venous pulsation: possible risk indicator in normal tension glaucoma? Acta Ophthalmol. 2013;91(6):514-20.

32. Stodtmeister $R$. The pulsation and the pressure of the central retinal vein and their relation to glaucoma damage and therapy. Klin Monbl Augenheilkd. 2008;225(7):632-6.

33. Stodtmeister R, Ventzke S, Spoerl E, Boehm AG, Terai N, Haustein M, et al. Enhanced pressure in the central retinal vein decreases the perfusion pressure in the prelaminar region of the optic nerve head. Invest Ophthalmol Vis Sci. 2013;54(7):4698-704.

34. Ulrich WD. Grundlagen und Methodik der Ophthalmodynamometrie (ODM), Ophthalmodynamographie (ODG), Temporalisdynamographie (TDG), vol. 44. Leipzig: VEB Georg Thieme; 1976.

35. Löw UG. Kalibrierung des Kontaktglasdynamometers an enukleierten Schweineaugen und klinischer Vergleich zwischen dem Kontaktglasdynamometer und der Smartlens. 2002, Medizinische Fakultaet der Universitaet des Saarlandes. Reference type: thesis/dissertation.

36. Morgan WH, Cringle SJ, Kang MH, Pandav S, Balaratnasingam C, Ezekial D, et al. Optimizing the calibration and interpretation of dynamic ocular force measurements. Graefes Arch Clin Exp Ophthalmol. 2010;248(3):401-7.

37. Legler $U$, Jonas JB. Frequency of spontaneous pulsations of the central retinal vein in glaucoma. J Glaucoma. 2009;18(3):210-2.
38. Inaba Y, Ohkubo T, Uchiyama S, Kunugita N. Determination of amounts of tar, nicotine, carbon monoxide, and tobacco-specific nitrosamines in the fillers of and mainstream smoke from privately imported cigarettes. Nihon Eiseigaku Zasshi. 2014;69(3):205-10.

39. Light A, Grass C, Pursley D, Krause J. Carboxyhemoglobin levels in smokers vs. non-smokers in a smoking environment. Respiraroty Care J. 2007:52(11):1576

40. Cellina GU, Honour AJ, Littler WA. Direct arterial pressure, heart rate, and electrocardiogram during cigarette smoking in unrestricted patients. Am Heart J. 1975;89(1):18-25.

41. Machado Vde S, Valadares AL, Costa-Paiva L, de Sousa MH, Pinto-Neto AM. Factors associated with the onset of hypertension in women of 50 years of age or more in a city in Southeastern Brazil. Rev Bras Ginecol Obstet. 2014;36(10):467-72.

42. Leone A. Does smoking act as a friend or enemy of blood pressure? Let release Pandora's box. Cardiol Res Pract. 2011;2011:264894. doi:10.4061/ 2011/264894.

43. Herberg $\sqcup$, Montgomery AM, Rose IC. Tolerance and sensitization to stimulant and depressant effects of nicotine in intracranial self-stimulation in the rat. Behav Pharmacol. 1993;4(4):419-27.

44. Rångemark C, Wennmalm A. Endothelium-dependent and-independent vasodilation and reactive hyperemia in healthy smokers. J Cardiovasc Pharmacol. 1992;20 Suppl 12:189-201.

\section{Submit your next manuscript to BioMed Central and take full advantage of:}

- Convenient online submission

- Thorough peer review

- No space constraints or color figure charges

- Immediate publication on acceptance

- Inclusion in PubMed, CAS, Scopus and Google Scholar

- Research which is freely available for redistribution 